CONFERENCE REPORT

\title{
Treatment of hepatitis C. The 2002 French consensus
}

\author{
D Dhumeaux, P Marcellin, E Lerebours
}

Gut 2003;52:1784-1787

C hronic infection by hepatitis C virus (HCV) affects 170 million people worldwide. In European countries the overall prevalence in adults ranges from $1 \%$ to $2 \%,{ }^{12}$ and more than five million Europeans are thus infected. The high prevalence of HCV infection, together with the risk of severe complications which include cirrhosis and hepatocellular carcinoma, ${ }^{3}{ }^{4}$ makes this a major public health problem.

HCV was discovered more than 10 years ago, and considerable progress has since been made in our knowledge of the virus, its modes of transmission, the natural history of the infection, and also patient management, including specific therapy. Several consensus conferences have been organised in the last five years, in particular the French Association for the Study of the Liver in January 1997, the National Institutes of Health in March 1997, ${ }^{6}$ and the European Association for the Study of the Liver (EASL) in February 1999. ${ }^{7}$ Major changes have since occurred in the epidemiology of the infection and in patient management.

Firstly, recent surveys show profound changes in the characteristics of newly diagnosed patients: the proportion of patients with mild chronic hepatitis at diagnosis has increased, and the absolute number of severe cases-that is, with cirrhosis and hepatocellular carcinoma-has also increased, ${ }^{89}$ a large proportion of patients having been infected several decades previously. The modes of HCV transmission have also evolved, with a gradual reduction in the proportion of cases related to transfusion and an increase in the proportion related to intravenous drug use. These changes largely account for the observed changes in the HCV genotype profile, characterised by an increase in the prevalence of genotype 3 infection, which is associated with a better response to treatment.

Secondly, since the 1999 EASL consensus conference, new advances have been made in the treatment of chronic hepatitis $\mathrm{C}$, with the introduction of pegylated interferon (PEG IFN) which, in combination with ribavirin, gives an overall rate of sustained virological response of $55 \%$ (approximately $45 \%$ for HCV genotype 1 and $80 \%$ for HCV genotypes 2 and 3). ${ }^{10}$ It has also been shown in long term follow up studies that patients with sustained virological responses can be considered cured of the infection. ${ }^{12}{ }^{13}$

Thirdly, the information provided to HCV infected individuals has considerably improved, making patients more aware and better placed to participate in the management of their disease. For example, knowing that treatment efficacy has improved, some patients may insist they receive curative treatment even if they have little liver damage. More generally, the treatment target is tending to shift from the clinical disease itself (that is, the hepatic lesions of chronic hepatitis C) to the underlying viral infection. This change may have a significant impact on the indications of pretreatment investigations, and especially liver biopsy.

Fourthly, some patients have extensive fibrosis or cirrhosis at diagnosis. When treatment fails to induce a virological response, the question arises as to the need for "maintenance treatment" aimed at limiting disease progression and the risk of hepatocellular carcinoma.
Fifthly, the management of patients infected both by HCV and by human immunodeficiency virus (HIV) has changed with the improved efficacy of antiretroviral therapy, which has transformed the prognosis of HIV disease and, as a consequence, revealed the impact of $\mathrm{HCV}$ infection on mortality in this particular setting.

Finally, the management of intravenous drug users has markedly evolved, especially with the introduction of replacement therapy and a trend towards community based "holistic" approaches.

With the aim of assessing these changes and optimising the management strategy for HCV infected patients, a new consensus conference was held in Paris on 27-28 February 2002. ${ }^{14}$ The recommendations elaborated in this conference are directed towards all physicians caring for patients with HCV infection, including internists, general practitioners, and specialists in hepatology, gastroenterology, and infectious diseases.

This consensus conference followed the methodological rules developed by the French Agence Nationale d'Accréditation et d'Evaluation en Santé. It consisted of an organising committee of academic scientists, a working group who prepared the information for the jury, the experts themselves, and an independent jury composed of persons not involved in the study of HCV or in patient management (see appendix).

As required by the organising committee, this conference was entirely financed by funds from the public sector. It took the form of:

(a) presentations by experts working in areas relevant to the consensus questions, during a public session;

(b) questions from and discussions among conference attendees; and

(c) closed deliberations by the jury, followed by the writing of conclusions and recommendations (available from http://afef.meditis.net and ${ }^{14}$ ).

The five questions put to the jury were:

(1) Which patients should be treated?

(2) What are the most appropriate investigations before treatment?

(3) Which is the optimal treatment?

(4) How to monitor treated patients?

(5) How to monitor untreated patients?

\section{WHICH PATIENTS SHOULD BE TREATED?}

The introduction of new drugs or new drug combinations with better efficacy may modify the treatment indications in

Abbreviations: $\mathrm{HCV}$, hepatitis $\mathrm{C}$ virus; PEG IFN, pegylated interferon; HIV, human immunodeficiency virus 
HCV infection. In this respect, the advent of the PEG IFN/ ribavirin combination is important to consider. Although not excluding broader indications, the jury recalled that therapy must preferentially be offered to those patients with the best predicted risk-benefit ratio. Treatment indications remain based on histological assessment of hepatic lesions. Although high grade histological activity may be associated with accelerated disease progression, the severity of chronic hepatitis $\mathrm{C}$ is mainly defined by the stage of fibrosis. The jury thus considered that, whatever the grade of necroinflammatory activity, patients with stage F2 or F3 fibrosis (METAVIR scoring system) have the best potential riskbenefit ratio and are thus the best candidates for treatment.

With regard to patients with mild chronic hepatitis (F0 or F1) or chronic HCV infection associated with repeatedly normal transaminase levels (a situation in which histological lesions are also generally mild), the risk of disease progression is low and the long term benefits of treatment have not yet been established. Previous consensus conferences did not recommend treatment for these patients. However, it was recently found that combined therapy was highly effective in patients infected with HCV genotype 2 or 3 . Thus the jury recommended that patients with mild hepatitis should not be excluded from treatment, provided they are infected by HCV genotype 2 or 3.

Patients with cirrhosis generally responded poorly to previous treatments. This situation could change with the advent of new agents such as PEG IFN, which is effective in a significant proportion of cirrhotic patients. ${ }^{15}$ The jury recommended that these patients should not be excluded from treatment, and that some of them (those with a biochemical response to treatment but without viral eradication) qualify for "maintenance therapy" in an attempt to delay disease progression pending the development of new drugs. ${ }^{16-18}$ The jury recommended PEG IFN monotherapy (without ribavirin) for this "maintenance therapy", as it can maintain a biochemical response and seems to be better tolerated than combination therapy. ${ }^{19}$ Specific doses of PEG IFN could not be recommended in the absence of relevant data. This maintenance therapy was also recommended for patients with extensive fibrosis (stage F3 in the METAVIR scoring system). The jury stressed that this strategy remains to be validated and that, whenever possible, such patients should be enrolled in clinical trials. This example clearly illustrates the fact that there are now two distinct treatment aims:

(a) ideally, to eradicate the virus-that is, to cure the infection; and

(b) to prevent, stabilise, or even improve hepatic lesions.

All meta-analyses of studies involving patients with acute hepatitis have shown that therapy reduces the rate of progression to chronicity, and previous consensus statements recommend that these patients should be treated. Two studies have now reported a very high success rate-better than $80 \%$-in patients treated with relatively high doses of standard interferon, given daily (at least at the beginning of treatment). ${ }^{20}{ }^{21}$ The jury thus recommended this treatment protocol, but stated that the effects of PEG IFN, alone or in combination with ribavirin, must rapidly be assessed with the aim of obtaining similar or even better efficacy.

In previous consensus conferences, HCV infected intravenous drug users were not considered as a treatment priority. Recent changes in the global management of these patients, including replacement therapy, are modifying this view. Ongoing excessive alcohol consumption, concomitant HIV or HBV infection, psychiatric disorders, and social precariousness frequently worsen the prognosis of HCV infected intravenous drug users, but the jury noted that they also have a number of favourable characteristics for treatment; indeed, diagnosis is generally made at a relatively young age, the prior duration of HCV infection is relatively short, histological lesions are usually mild, and the prevalence of genotype 3 infection is high. Given these factors, therapeutic indications in drug users could be broader than previously proposed.

The increased efficacy of antiretroviral drugs in HIV infection has also challenged previous restrictions on the indications for HCV treatment in HCV/HIV coinfected patients. Indeed, some patients who respond well to treatment for HIV infection may now die from HCV disease. The jury therefore recommended that coinfected patients with moderate to severe histological fibrosis should not be excluded from HCV treatment but stressed the risk of interactions between ribavirin and other nucleoside analogues, and the possible potentiation of antiretroviral hepatotoxicity by underlying liver disease.

\section{WHAT ARE THE MOST APPROPRIATE INVESTIGATIONS BEFORE TREATMENT?}

In addition to standard tests, special attention should be paid to extrahepatic manifestations, psychiatric disorders, HIV coinfection, excessive alcohol consumption and, as recently emphasised, excess body weight. As recommended by a previous conference, ${ }^{7}$ HCV genotypes and HCV RNA levels must be determined before treatment. The HCV genotype influences both the treatment indications and the therapeutic strategy itself, as current treatments are more effective and shorter in patients with HCV genotype 2 or 3 infection. HCV RNA quantitative assay, at least in patients treated with the PEG IFN/ribavirin combination, is not used to define the duration of treatment but may be useful in patients infected by HCV genotype $1^{22}$ providing a baseline value on which to appreciate the early response, which is a good indicator of the likelihood of a sustained virological response.

A major point of discussion on the pretreatment workup was the place of liver biopsy. Clearly, liver biopsy is still the best way of evaluating fibrosis (the key parameter in prognostication and therapeutic decision making) and, as in previous conferences, the jury supported its use. However, given the good efficacy of treatment on some HCV genotypes, and reports that a fear of biopsy and its refusal by some patients may hamper access to treatment, the jury recommended that liver biopsy should not be mandatory when the decision to treat has already been taken and will not be affected by the histological result. This particularly concerns patients in whom the treatment aim is viral eradication, independently of histological lesions - that is:

(a) patients infected by HCV genotype 2 or 3, in whom efficacy is approximately $80 \%$ in clinical trials;

(b) women planning to become pregnant and wishing to avoid the (low) risk of transmitting HCV to their child;

(c) patients with symptomatic cryoglobulinaemia (viral eradication being crucial for symptom control); and

(d) HCV/HIV infected patients, when antiretroviral treatment can be postponed (the advantage in such cases is that treating HCV infection before HIV infection avoids interference between the drugs used for the two infections).

Serum markers of fibrosis have recently been proposed as an alternative to liver biopsy. ${ }^{23}{ }^{24}$ Some are not used routinely, and all must be validated in large studies and by different groups before being adopted. 


\section{WHAT IS THE OPTIMAL TREATMENT?}

As expected, the reference treatment proposed by the jury is the combination of PEG IFN and ribavirin. In this combination, the two types of PEG IFN, alpha-2a and alpha-2b, give similar results in terms of sustained virological responses. ${ }^{11} 11$ By analogy with the standard IFN plus ribavirin combination, the jury proposed 48 weeks of treatment for patients infected by genotype 1 and 24 weeks for patients infected by genotype 2 or 3 . The validity of this recommendation was confirmed at the 2002 EASL meeting. ${ }^{25}$ The jury also underlined the need to better define the optimal dose of the drugs used. In particular, they posed the question as to whether the dose of $1.5 \mathrm{mg} / \mathrm{kg} /$ week PEG IFN alpha- $2 \mathrm{~b}$, currently recommended for combined therapy, could be reduced. Indeed, with PEG IFN monotherapy, $1.0 \mathrm{mg} / \mathrm{kg}$ / week has the same efficacy as $1.5 \mathrm{mg} / \mathrm{kg} /$ week in terms of sustained virological responses. ${ }^{26}$ The jury also questioned whether a ribavirin dose higher than $10.6 \mathrm{mg} / \mathrm{kg} /$ day is really necessary for all patients, and whether the optimal doses might be modulated according to both the initial viral load and HCV genotype. Clearly, these questions call for further investigations.

Changes in viral load following treatment initiation have been shown to be predictive of the likelihood of a sustained virological response. In this respect, the most convincing result is that patients with HCV genotype 1 infection in whom viral load fails to become negative or to fall by more than two log after 12 weeks of treatment have a high likelihood of treatment failure. ${ }^{11}$ The jury concluded that if the objective is viral eradication, treatment can be stopped in such cases.

Certain factors influence both the response to treatment and HCV disease outcome. The jury proposed to take into account these factors in an overall patient management approach, whether or not treatment is indicated. Excessive alcohol consumption seems to be associated with increased viral replication and with resistance to antiviral treatment. It also accelerates the progression of liver disease. Like previous conferences, the jury recommended that patients be advised to abstain, or to drink no more than $10 \mathrm{~g} /$ day alcohol. Obesity is a risk factor for steatosis, which is associated with more rapid progression to fibrosis. It also lowers the treatment success rate. Weight reduction should thus be encouraged. Finally, because HCV/HBV coinfection is associated with a poorer prognosis, hepatitis $\mathrm{B}$ vaccination is recommended.

\section{HOW TO MONITOR TREATED AND UNTREATED PATIENTS?}

Patient monitoring during treatment must focus on drug efficacy and tolerability (with special attention to psychiatric disorders) and on quality of life. Proximity support is essential, in addition to regular visits to specialists. Efficacy is mainly assessed on the basis of biochemical tests (transaminase levels) and virological criteria. It has been shown that undetectable HCV RNA six months after treatment withdrawal corresponds in the vast majority of cases to permanent viral eradication. ${ }^{12}{ }^{13}$ The indications of quantitative HCV RNA assays depend on the viral genotype. As previously mentioned, a marked reduction in viral load at 12 weeks of treatment is predictive of a sustained virological response in patients infected by genotype 1 , and treatment should be adapted according to this result. ${ }^{22}$ Given the high probability of a sustained virological response, early viral RNA quantification is not warranted in patients infected by HCV genotype 2 or 3. An alternative to HCV RNA quantitation is measurement of HCV core antigen, but the current assay lacks sensitivity. Liver biopsy is not required for patients with a sustained virological response. Regarding non-responders, the jury recommended a new liver biopsy only if the histological result is likely to affect patient management. Clinical and biological monitoring must be reinforced in patients coinfected by HIV and HCV. Any sign of mitochondrial cytopathy (the risk of which appears to be increased by cirrhosis) calls for measurement of blood lactate and possibly a change in antiretroviral treatment. It is also essential to inform the patient and family of the impact of treatment on the quality of personal, family, social, and work relationships. Medical networks and patient associations have an important role to play in supporting treated patients. Training should be reinforced, and should involve general practitioners, gastroenterologists, nurses, psychologists, and social workers. Finally, the jury recommended that all clinical trials in HCV infection include an assessment of quality of life. ${ }^{19}$

When specific treatment is not indicated, the overall management goals are to detect changes in the infection and to provide the patient with regular information on the disease and its treatment, and lifestyle advice. Monitoring modalities will depend on the stage of hepatitis at diagnosis, the patient's age, and changes in transaminase levels. In this respect, the jury identified three main situations:

(1) The patient has no or mild lesions at liver biopsy: the risk of progression is low, and a new biopsy is not recommended before five years unless transaminase levels increase or cofactors favouring progression of fibrosis are found.

(2) Transaminase levels are persistently normal and liver biopsy has not been performed: half yearly transaminase assay suffices in such cases. Liver biopsy must be considered if transaminase levels increase.

(3) The patient has cirrhosis: based on usual practice, monitoring includes $\alpha$-fetoprotein measurement and abdominal sonography every six months (to detect hepatocellular carcinoma) and upper gastrointestinal endoscopy every l-4 years (to detect oesophageal or gastric varices).

We compared the jury's recommendations with those of the NIH consensus conference held on 10-12 June 2002, shortly after the French consensus conference. ${ }^{27}$ With the exception of a few minor differences, the two statements are very similar. The main difference concerns maintenance therapy; the French statement recommends it for some patients with severe liver disease who have a biochemical response to treatment, even without a virological response, in order to prevent, stabilise, or even improve hepatic lesions. This is based on several reports showing stabilisation of histological lesions, and a reduced incidence of complications, including hepatocellular carcinoma, in treated patients compared with untreated patients, especially when a biochemical response is obtained. ${ }^{16-18}$ However, in common with the US statement, the French statement emphasised the need for further trials to confirm the benefit of maintenance therapy.

It should also be noted that the jury's recommendations not only took into account evidence based advances in the treatment of hepatitis $\mathrm{C}$, but also integrated new patient management strategies, such as the possibility of treatment without biopsy and treatment of mild disease, which remains to be validated. It is important to note that patient advocacy group representatives sitting on the jury had a major say in these latter recommendations.

The story of hepatitis C continues. Throughout the conference, the jury carefully listed the numerous unsolved questions, and was fully aware that its recommendations could be revised in the more or less short term. Work in prospect for hepatologists and future consensus juries! 


\section{Authors' affiliations}

D Dhumeaux, Department of Hepatology and Gastroenterology, Henri Mondor Hospital, Créteil, France

P Marcellin, Department of Hepatology, Beaujon Hospital, Clichy, France

E Lerebours, Department of Gastroenterology, Charles Nicolle Hospital, Rouen, France

Correspondence to: Professor D Dhumeaux, Department of Hepatology and Gastroenterology, Henri Mondor Hospital, 51 av du Mal, de Lattre de Tassigny, Créteil 94000, France; daniel.dhumeaux@hmn. ap-hop-paris.fr

Accepted for publication 16 April 2003

\section{APPENDIX}

\section{Organising committee}

D Dhumeaux (President), P Marcellin (Secretary), JP Bronowicki, P Cacoub, P Calès, C Chidiac, P Couzigou, JC Desenclos, H Desmorat, E Dorval, P Dosquet, P Hillon, E Lerebours, F Lunel-Fabiani, L Piroth, S Pol, B Rivoal, D Samuel.

\section{Documentary group}

T Asselah, V De Lédinghen, JC Duclos-Vallée, F Durand, H Fontaine, A Gervais, J Gournay, JD Grangé, C Hézode, V Leroy, D Lucidarme, G Perlemuter.

\section{Experts}

P Bedossa, O Bernard, M Bourlière, JP Bronowicki, P Cacoub, P Couzigou, D Dhumeaux, B Filoche, D Larrey, P Marcellin, P Mathurin, P Mélin, JB Nousbaum, JM Pawlotsky, C Perrone, S Pol, T Poynard, F Roudot-Thoraval, D Samuel, L Serfaty, C Trépo, JC Trinchet, JP Zarski, F Zoulim.

\section{Jury}

E Lerebours (President), A Alpérovitch, A Biosse-Duplan,

D Caro, P Chavanet, P Cordein, A Degodet, J Denis, T Fontanges, M Garré, JJ Girard, M Kopp, B Pozzetto, R Systchenko, MJ Viaud.

\section{REFERENCES}

1 Trépo C, Pradat P. Hepatitis C virus infection in Western Europe. J Hepatol 1999;31(suppl 1):80-3.

2 Naoumov NV. Hepatitis C virus infection in Eastern Europe. J Hepatol 1999;31(suppl 1):84-7.

3 Marcellin P. Hepatitis C: the clinical spectrum of the disease. $J$ Hepatol 1999:31(suppl 1):9-16.

4 Alberti A, Chemello L, Benvegnu L. Natural history of hepatitis C. J Hepatol 1999;31(suppl 1):17-24.

5 Dhumeaux D, Doffoël M, Galmiche JP. A French consensus conference on hepatitis C: screening and treatment. J Hepatol 1997;27:941-4.
6 National Institutes of Health Consensus Development Conference Panel Statement: management of hepatitis C. Hepatology 1997;26/suppl 1):2S-10S.

7 EASL international consensus conference on hepatitis C. Paris, 26-27 February 1999. Consensus statement. J Hepatol 1999;31(suppl 1):3-8.

8 Fattovich G, Giustina G, Degos F, et al. Morbidity and mortality in compensated cirrhosis type C: a retrospective follow-up study of 384 patients. Gastroenterology 1997;112:463-72.

9 Deuffic S, Buffat L, Poynard T, et al. Modeling the hepatitis C virus epidemic in France. Hepatology 1999;29:1596-601.

10 Manns MP, McHutchison JG, Gordon SC, et al. Peginterferon alfa-2b plus ribavirin compared with interferon alfa- $2 b$ plus ribavirin for initial treatment of chronic hepatitis C: a randomised trial. Lancet 2001;358:958-65.

11 Fried MW, Shiffman ML, Reddy KR, et al. Peginterferon alfa-2a plus rivabirin for chronic hepatitis C virus infection. N Engl J Med 2002;347:975-82.

12 Marcellin P, Boyer N, Gervais A, et al. Long-term histologic improvement and loss of detectable intrahepatic HCV RNA in patients with chronic hepatitis C and sustained response to interferon-alpha therapy. Ann Intern Med 1997; 127:875-81.

13 Reichard O, Glaumann H, Fryden A, et al. Long-term follow-up of chronic hepatitis $C$ patients with sustained virological response to alpha-interferon. J Hepatol 1999;30:783-87.

14 Consensus conference. Treatment of hepatitis C. Gastroenterol Clin Biol 2002;26:B312-20.

15 Heathcote EJ, Shiffman ML, Cooksley GE, et al. Peginterferon alfa-2a in patients with chronic hepatitis $C$ and cirrhosis. N Engl J Med 2000;343:1673-80.

16 Shiffman ML, Hofmann CM, Thompson E, et al. Relationship between biochemical, virological and histological response during interferon treatment of chronic hepatitis C. Hepatology 1997;26:780-5.

17 Nishiguchi S, Kuroki T, Nakatani S, et al. Randomised trial of effects of interferon-a on incidence of hepatocellular carcinoma in chronic active hepatitis C with cirrhosis. Lancet 1995;346:1051-5.

18 Yoshida H, Shiratori Y, Moriyama M, et al. Interferon therapy reduces the risk for hepatocellular carcinoma: national surveillance program of cirrhotic and noncirrhotic patients with chronic hepatitis $C$ in Japan. Ann Intern Med 1999;131:174-81

19 Foster GR. Hepatitis $C$ virus infection: side effects and quality of life. $J$ Hepatol 1999:31(suppl 1):250-4.

20 Vogel W, Graziadei I, Umlauft F, et al. High-dose interferon-alpha2b treatment prevents chronicity in acute hepatitis C: a pilot study. Dig Dis Sci 1996;41(suppl):81S-85S.

21 Jaeckel E, Cornberg $M$, Wedemeyer $\mathrm{H}$, et al. Treatment of acute hepatitis $\mathrm{C}$ with interferon alfa-2b. N Engl J Med 2001;345:1452-7.

22 Pawlotsky JM. Use and interpretation of virological tests for hepatitis C. Hepatology 2002;36(suppl 1):S65-73.

23 Guéchot J, Loria A, Serfaty L, et al. Serum hyaluronan as a marker of liver fibrosis in chronic viral hepatitis C: effect of $\alpha$-interferon therapy. J Hepatol 1995;22:22-6

24 Imbert-Bismut F, Ratziu V, Pieroni L, et al. Biochemical markers of liver fibrosis in patients with hepatitis $C$ virus infection: a prospective study. Lancet 2001;357:1069-75.

25 Hadziyannis SJ, Cheinquer H, Morgan T, et al. Peginterferon alfa-2a (4OKD) (Pegasys) in combination with ribavirin (RBV): efficacy and safety results from a phase III, randomized, double-blind, multicentre study examining effect of duration of treatment and RBV dose. J Hepatol 2002;36(suppl 1):3.

26 Lindsay KL, Trépo C, Heintges T, et al. A randomized, double-blind trial comparing pegylated interferon alfa- $2 b$ to interferon alfa- $2 b$ as initial treatment for chronic hepatitis C. Hepatology 2001;34:395-403.

27 National Institutes of Health Consensus Development Conference Statement: management of hepatitis C: 2002. Hepatology 2002:36(suppl 1):S3-S20. 